\title{
Analysing outdoor airflow and pollution as a parameter to assess the compatibility of mass-scale low-cost residential development
}

\author{
Arnab Jana* \\ Centre for Urban Science and Engineering, \\ Indian Institute of Technology Bombay, Mumbai 400076, India. \\ Email: arnab.jana@iitb.ac.in \\ Phone: +9122 25769331 \\ Ahana Sarkar \\ Centre for Urban Science and Engineering, \\ Indian Institute of Technology Bombay, Mumbai 400076, India. \\ Email: ahana.sarkar@iitb.ac.in \\ Phone: +9122 25769301 \\ Ronita Bardhan \\ Sustainable Design Group-Behaviour and Building Performance, \\ Department of Architecture, \\ University of Cambridge, Cambridge, CB2 1PX, United Kingdom, \\ Email: rb867@cam.ac.uk \\ Phone: 01223332969 \\ and \\ Centre for Urban Science and Engineering, \\ Indian Institute of Technology Bombay, Mumbai 400076, India.
}

*corresponding author

Declaration of interest: None 
1 Analysing outdoor airflow and pollution as a parameter to assess the compatibility of mass-scale 2 low-cost residential development

3 Abstract

4 Land use compatibility has always remained an integrally crucial factor for city development. 5 Traditional contentious theories integrating land use planning principles, demand-oriented market 6 development and industry-induced air pollution regulations have debated the adjacency of residential 7 and industrial land uses. However, in the event of inevitable and unprecedented urbanization, where 8 land shortage has compelled cities to expand towards the industrial peripheries, low-income 9 resettlement planning turns evident. However, this process turns detrimental when land use liveability, ultimately forcing the population to vacate the housing and recur poverty recycling phenomenon. This study aims to assess micro-level land-use compatibility from health and liveability viewpoint using environment-based computational fluid dynamics (CFD) analysis as a surrogate measurement technique. It is assumed that if site-based ventilation potential and airflow assessment can be performed at early design for site-selection and post-construction stages for rational retrofitting, it would deliver a liveable environment to the low-income inhabitants. While industrial development is irresistible, this study focused on environment-sensitive built-environment planning, utilising aerodynamically potential morpho-metrics of urban form density, inter-building gaps and integrated open spaces. Simulated results demonstrated that while existing built-environment planning failed to deliver improved ventilation, the simulation-based approach of iterated built-environment designs created air channelling and pollutant transport paths, thus reducing the air pollution stagnancy quotient. This study, by applying a system-driven methodological approach aided in bridging the knowledge gaps of micro-level land use compatibility assessment from environmental perspective and health viewpoint.

Keywords: Land use incompatibility; health and well-being; low-income; mass-scale housing; computational fluid dynamics (CFD); airflow and pollution; built-environment.

\section{Introduction}

Land-use compatibility has always remained an integrally crucial factor in urban sectors, often igniting an eternal conflict between humankind and land. While Hong Kong adopted land reuse and reclamation strategy as a sustenance measure (Wang., Shen., Tang., \& Skitmore. 2013), resettlement phenomenon has become evident in metro-cities of developing nations like India. However, land-use compatibility, ecological environment and even landscape of the newly developed and resettled land and adjoining land-use often remain unassessed and overlooked in current land use planning guidelines.

The growth of cities is a universal process, as part of which the low-income group (LIG) becomes the inevitable surplus. In response to this context, housing authorities and state government agencies tend to develop hyper-dense low-cost mass-scale housing for the LIG and economically weaker section (EWS). Nevertheless, the problem arises when these low-cost mass-scale housing strategies ultimately deteriorate the liveability of intended population leading to 'rebound' (Debnath, Bardhan, \& Sunikkablank, 2019) (Sarkar, \& Bardhan., 2020b) and 'poverty recycling' phenomenon (Jones, 2017; Sholihah \& Shaojun, 2018).

Liveability, the idea which implies the ability of living space to support well-being, despite being a vital factor, remains under-researched in low-income neighbourhoods. Reduced liveability in low-income settlements include deplorable living conditions like poorly built housing structure on inferior contaminated or disaster-prone and disadvantaged sites etc. Degraded living condition often exposes the low-income people disproportionately to health risks (Govender, Barnes, \& Pieper, 2011). Literature 
on temporal and intersectional concerns of liveability encompasses various domains of social cohesion, belongingness, privacy and safety, education, employment, housing, leisure and culture which are not only subject to change but also depends on population cohort (Badland et al., 2014). However, this study expresses liveability as the essential context where one's basic health and physical condition would not deteriorate among low-income sector.

The key challenge lies in ensuring that low-cost mass-scale residential development does not come at the cost of existing ecological conditions and more importantly, at the expense of the liveability and health of the disadvantaged population. Lack of land-use compatibility, ecological sustainability and liveability assessment have risked the neighbouring ecological milieu on one hand and more significantly the health and well-being of the current low-income population residing in the newly developed sites on the other hand. This alarming situation has called for the necessity of liveability assessment through land-use compatibility and spatial complexity measurement.

Mumbai metropolitan-city had stabilized population growth in last two decades, yet, $52.5 \%$ of the city population reside in slums occupying only nine per cent of the city's area (Weinstein, 2012). Given the current focus of affordable housing authorities on formulating slum rehabilitation schemes and more importantly on the development of low-cost mass housing, the Development Plan for Greater Mumbai 2014-2034: Preparatory Studies reported that "Given the severely constrained supply of land and high population density, obtaining land for public purpose in Greater Mumbai is extremely challenging". Hence, Mumbai turns to be a prominent case currently experiencing two types of low-income housing development phenomenon- i) in-situ development, where the slum households undergo up-gradation locally, with housing and basic infrastructure improvement, and ii) altered movement, where the land parcels are procured by the state government to develop infrastructure projects, resulting in the wide eviction of the inhabitants and resettling them to rehabilitation housing elsewhere under Project Affected People (PAP) scheme (Bardhan, Sarkar, Jana, \& Velaga, 2015).

Often under conditions of severe land shortage, the government is continually searching for means of procuring enough land to meet the escalating housing shortage demands. Nevertheless, the government initially in the lieu of performing a trade-off between cost and availability of land, sometimes ignore the principles of land use compatibility ultimately jeopardising the health and liveability of the intended residents. These instances are currently witnessed in Mumbai when some of the disadvantaged population demanded to shift to other locations, or tend to rent out and vacate the mass housing not only due to the regular socio-economic incompatibility but majorly due to degraded health conditions. This 'rebound' phenomenon turns detrimental to the government authorities, not only by nullifying the cost of land and vacated housing but also in the process of resettling the population again, thus mounting the economic burden.

Recognising the key roles played by land-use decisions in controlling the ecological setting and microenvironment of the developed land has the potential to contribute to innovative approaches to formulate more effective land-use planning policies for forthcoming low-cost mass-scale housing development projects. Moreover, the current land-use planning guidelines require an efficacy and compatibility assessment tool for evaluating risks to neighbouring landscape on one hand and health and liveability of the target population on the other hand.

Urbanisation has been repeatedly cited as a driver of disconnection from nature, although careful planning and management of urban infrastructure can assist in improving the urban functioning (Andersson et al. 2014). This study aligning with the above theory, attempts to treat cities as a socioecological system, in which both subsystems are equally important and their sensitive development determines liveability in the city. 
The novelty of this study lies in considering land-use conflict as an inescapable event and investigating an optimum route to solve the pressing issue. Understanding the current land-use setting of low-income mass housing archetype on one hand and their micro-climatic condition, on the other hand, would aid in identifying the role of land-use parcelling and especially morphological design in modulating the environmental characteristics, which would, in turn, have an indirect impact on occupant health and liveability. This study attempts to adopt a health and liveability perspective on land-use compatibility assessment taking Mumbai slum rehabilitation housing as a case study. It tries to address the research question - how micro-climatic condition particularly site-based airflow distribution acts as a criterion to assess the residential-industrial land-use compatibility? The evaluation technique applied here elucidates how urban ecology and morphology interlinkage impacts land use compatibility to ensure an improved and healthy environment in low cost mass housing land? Objectively this study aims to a) understand the locational and land use setting differences among low-cost mass housing archetypes, as a comparative analysis would enable in identifying the differences in land-use parcelling as well as the quotient of healthy environment, b) how land-use incompatibility has changed the micro-climate and environmental condition in these existing areas, $\underline{\text { ae) }}$ understand which morphological attributes can be applied as policy variables to take careful land-use decisions and improve the environmental condition of this socio-ecological setup, and $\mathrm{d}$ ) ) to identify a feasible land-use planning approach where all systems can co-exist. This study, by beholding the notion of socio-ecological system, bridges together urban morphology and environmental planning analysis, and further puts forward convincing morphological indicator-based proposals that would make residential buildings in peripheral environment-sensitive zones more 'liveable'. The inferences from this study extend conventional understandings of land-use compatibility to account for crucial health concerns affecting low-income disadvantaged populations. This would aid in formulating and revising forth-coming land-use policy guidelines in cities of developing nations, especially in the global south.

\section{Literature Review}

Socio-anthropological theories explicated that 'measures in the change in social organization are strongly associated with measures of change in land-use'(Bellamy \& Foster, 1999; Axinn \& Ghimire, 2011). While the resettled population condition their displacement with the guarantee of seeing improvement in their standard of living as observed in Lao PDR (Romagny, 2004), this often remains unfulfilled. The key-aspect of 'change in land use' associated with 'change in social organisation' is rarely ventured in the theories of 'displacement'. Inefficient space design, poor planning, operation and monitoring coupled with other socio-political challenges during low-income mass housing development has caused socio-spatial injustice resulting in degraded 'spatialisation' (Lefebvre, 1991), impoverishment and disruption of social fabric among the marginalised sector_Sarkar, \& Bardhan., 2020b). Established theories like four-stage Scudder-Colson diachronic theoretical model of lowincome settlement (Michael M. Cernea, 1995), later evolved Impoverishment of Risks and Reconstruction (IRR) Model (Cernea, 1997), as well as their contested researches (Aboda, Mugagga, Byakagaba, \& Nabanoga, 2019), recognised potential key-risks of low-income especially displaced population, however, barely considering the aspect of 'change in land-use' and its impact on inhabitants' health and liveability. On the other hand, theories like 'Levebvre's production of social space', 'Mercer Quality of Living Indicators' and 'Clements-Croome et al., (2017)s' SuBET planning tools' emphasised that health and liveability is a subject of geographical form, land-use, builtenvironment and environmental setting.

\subsection{Land use compatibility of low-cost residential development}


Mainstream theoretical underpinnings on urban morphology and industrial land use locations including concentric ring theory by Burgess, 1926, sector theory by Hoyt, 1939 and multi-nucleated zones theory by Harris and Ullman, 1945 have always planned low-income settlements close to the industrial zones. Contrastingly, the later-evolved land-use zoning bodies and regulatory authorities restricted the residential development close to the red industrial zones. Hence, with industrialization, the industries following 'firm occupy facilities' principles were observed to shift to the peripheries on one hand. On the other hand, with escalated urbanisation the residential and mixed-use boundaries gradually expanded and crossed the peripheral industrial land-use boundaries, thus leading to the emergence of land use-environment integration as well as conflict.

The traditional land-use planning principles like Jabotabek plan in the late 1970s for greater Jakarta metropolitan region suggested a fundamental policy message that land use management must be dramatically improved to reduce the negative impacts of land-use changes and urban-industrial conflicts for an environmentally sustainable development. Yet, the subsequent land development programmes initiated 'negative' land use controls through zoning laws on one hand, and unrestrained private sector land use on the other hand. Consequently, the Jabotaek plan despite having environment as one of its concerns failed to institute a decision-making process capable of overcoming the obstacles in the way of sound environmental management through land-use planning in the existing situation. The major difficulties included i) absence of effective coordination between government bureaux charged with aspects of land-use management, ii) absence of initiatives to guide private land development away from environment-sensitive zones, and iii) lack of political will to implement existing regulations (Douglass., 1989).

Land use compatibility assessment has been widely researched while measuring noise pollution levels surrounding an airport (Kiani, Nassiri, Hosseini, \& Monavari, 2014). Compatibility evaluation model (CEM) approach using multi-criteria evaluation analysis method has been utilised for evaluating different levels of physical compatibility of multi-functional and intensive urban land uses both horizontally and vertically (Taleai, Sharifi, Sliuzas, \& Mesgari, 2007). Recent improvements in landuse zone compatibility assessment methods include public participatory mapping involving consistency, conflict potential, zoning compatibility and sensitivity analysis (Brown, Sanders, \& Reed, 2018; Karimi \& Brown, 2017). Raman \& Roy, (2019) proposed a taxonomy of urban morpho-metrics suchlike scale, composition, compatibility, degree of mixing, density while assessing levels of land-use planning. Expert-system approaches have been implemented while analysing the non-productive landuse (Šalkauskienè, Gudritienè, \& Abalikštienè, 2019). Wang., Shen., Tang., \& Skitmore. (2013) utilised a coupled approach of GIS-MCDM for supporting land-use decisions to investigate the environmental aspect in five redevelopment sites of Hong Kong. Use of heavy computation-based algorithms are nowadays widely used for land-use spatial optimum location-allocation modelling (Huang \& Song, 2019; Jana, Bardhan, Sarkar, \& Kumar, 2016).

While tools for land-use compatibility assessment has been widely ventured, a speck of researches elucidating its interlinkage with health condition highlights the blind-spot in land-use compatibility literature. A recent study on Chinese cities revealed that the pollution-intensive industrial agglomeration directly impacted low-income urban residents' health expenditure, however, recommended to reduce it by strengthening environmental infrastructure (Li., Lu., \& Li. 2020). Yet most researches are restricted in the identification of consequences of incompatible land-use mix, while not looking at the feasible optimised solutions.

\subsection{Outdoor ventilation: Metric of micro-level land use compatibility assessment}


While land use compatibility might be dependent on several factors, a significant but rarely ventured parameter is the quality of air and outdoor ventilation potential. Especially in currently unavoidable fallouts of unprecedented urbanisation, where heavy polluting industrial belt share lands or adjacency with mass-scale residential plots, the prevalent direction of airflow, ventilation potential, the composition of air quality and more importantly, the severity of health issues that might affect the liveability of the population should be predicted and tested. Also, it is well-acknowledged in-the literature evinces -that effective-efficient natural ventilation strategies-can comprehensively $\underline{\text { hugely }}$ impact-influence comfort within the built-environment. Natural ventilation driven site-based air movement flow distribution apart fromcan improveing indoor air quality, and thermal comfort also-on one hand and reduces health cost up to $18 \%$, on the other hand (Dutton, et al., 2013).

Experimental and observation-based studies have witnessed that these current low-income mass housing tenements in Mumbai are defined by inefficient indoor air path, leading to poor indoor air quality (Sarkar \& Bardhan, 2019a, 2019b, 2020a), high air temperature trapped zones (Bardhan, Debnath, Malik, \& Sarkar, 2018) and low pollution disposal rates (Lueker, Bardhan, Sarkar, \& Norford, 2020). While looking for the contributors, it was observed that poor land use aggregation has degraded living condition in these housing since most of the affordable housing colonies are placed in close proximity to low-cost unhealthy sites such as garbage sites, dump-yards, petroleum refinery, medical waste incinerators, chemical factories or are located adjacent to mangroves and coastal lines. This phenomenon has inadvertently deteriorated the living condition from the aerodynamic and ecoenvironmental viewpoint.

While some critical reviews on the effect of air pollution control regulations on land use planning have discussed issues regarding the socio-economic impacts of constraining land use in the name of air quality, on one hand, the others deal with conflicting environmental goals and optimal allocation of land to achieve local and regional growth (Roberts et al., 1975). Adequate researches on integrating land use planning and meta-level air pollution levels have established the connection between land-use changes, spatial density, distribution of contribution of air pollutants, ventilation effects and thermal landscape (Basagaña, Rivera, Aguilera, Agis, \& Bouso, 2012; Romero, Ihl, Rivera, Zalazar, \& Azocar, 1999; Weng \& Yang, 2006). Yet, these studies lack the local-level land use compatibility assessment coupled with micro-climate examination and the severity of infeasible land use aggregation.

\subsection{Urban morphology: An approach to modify outdoor ventilation}

The phenomenon of high-rise compact design of cities often results in environmental degradation including the trapping of pollutants and stale air in the urban canopy (layer) i.e. the distance between the urban land and building height. Considering the recent milieu of climate change and urban development, the cohesive environmental-design is the most efficient avenue for warranting health and comfort to the citizens (Merlier, Kuznik, Rusaouën, \& Salat, 2018).

Built-environment at micro-level intensifies the environment-related problems since apart from increasing thermal capacity they also increase surface roughness, de-shaping airflow in the urban boundary layer especially, in the urban canopy layer (UCL) (Zhou, Wang, Chen, Jiang, \& Pei, 2014). The decreased airflow advertently leading to reduced ventilation effectiveness, increased heat stress and extreme indoor pollution levels (Lueker, Bardhan, Sarkar, \& Norford, 2020) in urban areas affect human morbidity levels (Bardhan, Debnath, Jana, \& Norford, 2018). This turns exigent for low-income sector who holds two-third of the city population, and where financial constraints curb the residents from utilising active cooling techniques to achieve desirable thermal comfort levels. 
Despite complication of urban air flows owing to complex urban built-forms, turbulence and multiscale and multi-physic qualities of urban atmospheric phenomenon, the morpho-metric of building disposition or urban porosity is an elementary urban element and crucial to thermal comfort, external airflow features, natural ventilation potential and micro-level building energy performance (Mei et al., 2017). Urban morphology, represented as a three-dimensional texture composed of a conscious arrangement of built-bodies and unbuilt volumes have often been characterised from an aerodynamic viewpoint for inducing direct and effective air paths (Chan \& Liu, 2018). Aerodynamic conditions resulting from the urban form-wind flow interaction sturdily impact pedestrian-level wind pattern and thermal comfort by generating turbulence and convective heat and mass transfers, ventilation potential of urban areas through urban heat island phenomenon and pollution dispersion and building energy consumption pattern (Cheung \& Liu, 2011).

Urban microclimate related complex airflows have been widely modelled using Computational Fluid Dynamics (CFD) by urban physicists, wind engineers and climatologists (Montazeri, Blocken, Janssen, \& Hooff, 2012). CFD has been employed as an established tool for modelling airflow around buildings, thermal comfort, pollutant dispersion (Ma, Jiang, \& Li, 2015), indoor air quality (Sarkar \& Bardhan, 2018, 2019a), humidity (Kim et al., 2008) etc. Besides, CFD can be used efficiently for performing parametric studies (Yuan \& Ng, 2012).

\subsection{Hypothesis of the study}

While on one hand, the traditional land-use principles proposed to settle the low-income blue-collared sector near the industrial belts to reduce the transport-oriented impediment (Approach A), the later evolved land-use zoning regulatory authorities recommended complete abandonment of residential land adjacent to the red industrial zones (Approach B) (see Figure 1). However, in the current unavoidable event of unprecedented urbanisation, this study proposed a conceptual scenario (Approach C in Figure 1) where residential sectors can share adjacency with industrial land-use, provided i) the severity of land-use incompatibility is assessed before zoning, ii) the industry-sourced polluted air-plume does not affect adjacent land, and iii) in the incident of susceptibility to the pollution, the industry-induced airplume direction should be examined and the adjoining morphological design should be sensitive enough to detour the incoming pollutant transport path. Subjective interpretation of this framework elucidates emitting from the adjacent industry. 


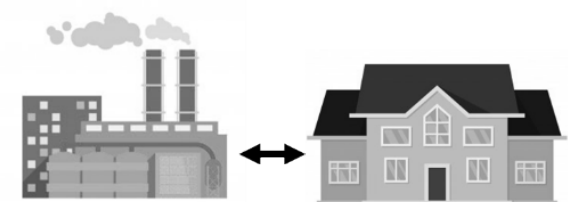

Approach A

(Close proximity between industrial and residential land use)

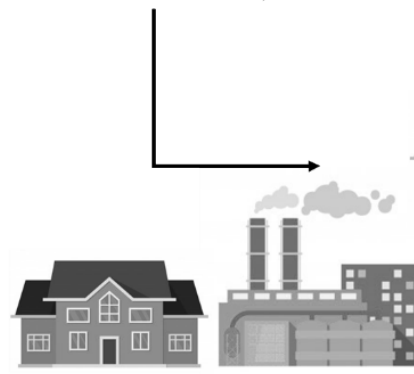

Residential land use at invulnerable zone

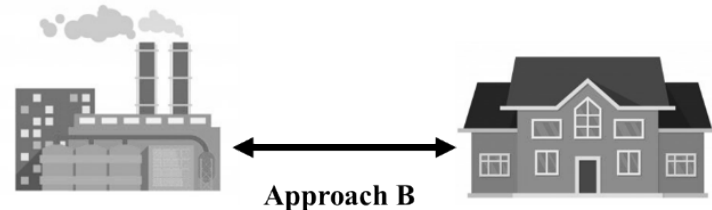

(High distance between industrial and residential land use)

Figure 1 Graphical representation of the hypothesis.

Toed in Figure 1, it can be hypothesised that 'rational urban morphology and environmental planning interaction can minimise the severity of industrial-residential land-use incongruity, thereby reducing the health and liveability concerned risk on population.'

\section{Study Area: Slum Rehabilitation Housing in Mumbai}

The recent Slum Rehabilitation Housing (SRHs) in Mumbai are typically $\underline{\text { represented as tall structures, }}$ ranging from-5-30 floors high with apartment units less than $25 \mathrm{~m}^{2}$. Through $\underline{T}$ the sucessful-recently formulated slum rehabilitation processscheme has benefitted, the slum dwellers are benefitted-with provision to-individual-level basic infrastructure, land tenure, access to the capital in the form of property. In the following section, two Mumbai based case studies representing typical compact midto-high rise low-income housing $\underline{\mathrm{SRH}}$ typologies have been represented (see Figure 2).

\section{Natwar Parekh SRH colony}

Natwar Parekh colony, manifesting typical SRH colonies of Mumbai, was constructed in 2008 and eontains consists of 4800 dwellings across 50 blocks. Here, apartments are accessed viaby single-loaded corridors along the dwelling perimeters, with toilets and bathing rooms abutting an internalcore ventilation shaft or void. Natwar Parekh SRH, built under in-situ SR programme, is surrounded by lowrise slums on one side and co-operative housing as well as luxury apartments on the other side. Other mixed-use retail and commercial retail include banks, non-polluting industries, garages and go-downs of leather products, highlighting the presence of compatible land use.

\section{Mahul PAP Township}

The Mahul Project Affected Persons (PAP) Township near Trombay belt of Mumbai, built under Slum Rehabilitation Authority (SRA)'s Development Control Regulation 33 (10) Clause 3.11, or the PAP scheme was selected as the second case study area. The SRH colony, consisting of 68 six, seven and eight floored buildings, covers a total area of approximately 160,000 sq. metre. The average maximum building height is about $18 \mathrm{~m}$ and $24 \mathrm{~m}$. The plan area density, $\lambda \mathrm{p}$ is 0.59 . The width of the street and 
side alleys ranges from $3 \mathrm{~m}$ to $4 \mathrm{~m}$, whereas the major vehicular road crossing the site measures $13 \mathrm{~m}$. The aspect ratio of the street canyons (H/W: Height of building/Width of the adjacent street) ranges from 6.25 to 8.33 . The vegetation levels are extremely low, and mostly located in the small courtyards and along the main streets.

Figure 2 shows the regional setting of Mahul PAP Township. The total area of the proposed land for SRH construction was $156,640.90$ sq. metre, out of which an area measuring $28,418.78$ sq. metre was in the possession of a multi-disciplinary nuclear research centre of national importance since 1963, as a buffer zone for security purposes. In April 2012, the centre objected to the scheme as it was falling under the buffer zone, and raised concerns about the scheme being a potential threat to national health and security. However, the numerous security concerns, cautions and objections raised by the centre and an oil and natural gas company regarding the proposal of the residential plot adjacent to the refinery was disregarded. Consequently, the land use of 'special industrial zone' was converted to 'residential zone' and rehabilitation buildings were constructed adjacent to the refinery. The state government authorities, while converting the land use category, however, imposed a condition of leaving a segregating set-back distance of only 52 metres between the polluting industrial and residential plot (Naik, 2018). The location of the township close to refineries, eco-sensitive zones of mangrove belts, industrial areas, and chemical storage complexes is a key contributor to pollution, affecting health and liveability. It also creates multiple hazards and scope for disaster and makes the entire area highly vulnerable and risky concerning social, economic, physical, medical, and environmental aspects. As a result, Mahul residents vehemently opposed to stay back and opted to vacate the apartments and shift elsewhere.

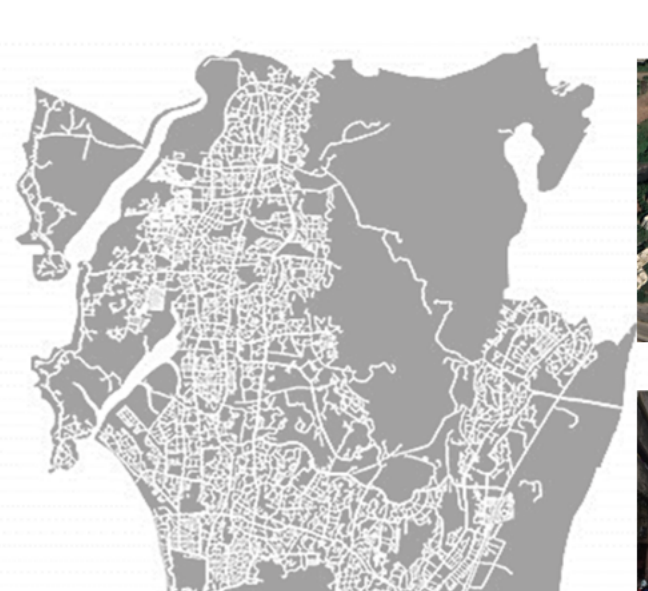

Natwar Parekh colony
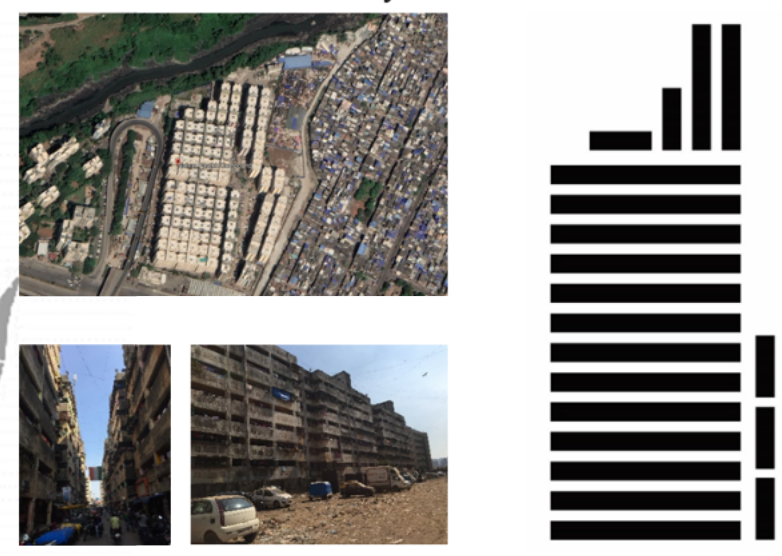

Mahul SRA colony
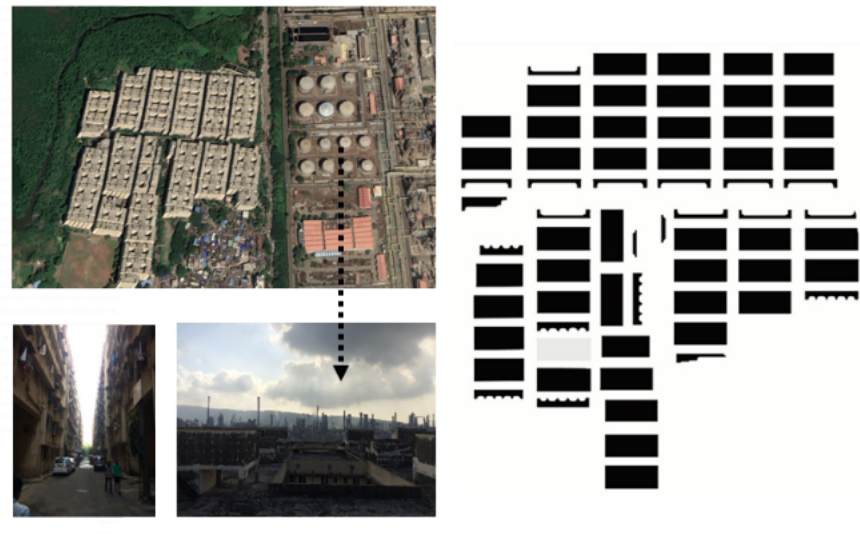

Figure 2 Regional setting of the case study areas. 


\section{Methodology}

A mixed-mode methodology was adoptedimplemented for evaluating land-use compatibility in the selected slum rehabilitation sites. Based-Framed on a sequential heuristic, this study forwards a systematic process-driven assessment approach drawn upon Mumbai SRH as case examples. The methodology treats urban development as a socio-ecological system, where both subsystems co-exist and conflicting land-use can share adjacent land parcels, however, solely after careful management and planning. This study, showing the route for cautious land-use planning is executed in five phases:

Phase 1: Investigating the challenges regarding land-use compatibility in affordable mass housing sites through literature review and global scenarios.

Phase 2: Examining the existing rehabilitation sites using outdoor ventilation and airflow distribution efficiency as a proxy measure of land-use compatibility.

Phase 3: Generating iterated hypothetical scenarios by varying criteria-driven urban morpho-metrics.

Phase 4: Examining and comparing land-use compatibility of the scenarios by estimating urban morpho-metrics and simulating outdoor ventilation as testing parameters.

Phase 5: Delivering recommendations at post-construction scenario which can improve the health and living condition of the rehabilitated population.

Here the methodology of assessing land-use compatibility offered two approaches: Approach 1 for preconstruction stage and Approach 2 for post-construction stage as seen in Figure 3. While preparatory land-use compatibility assessment becomes easy at the early design stage, the method of in-situ adaption turns challenging at post-construction stage.

In the case of a greenfield site (Approach 1 in Figure 3), after testing the severity of the effects of industrial-residential land-use incompatibility and conflict, careful planning and optimized land-use decisions can be undertaken. If the risks persist to be medium to high, the land can be deliberately restricted for residential development. While careful planning can be a feasible alternative if the risks are low. In this milieu, evidence-based urban morpho-metrics with high aerodynamic potential can be utilized to generate alternative scenarios, followed by analyzing their airflow distribution. By comparing the site-based airflow characteristics, wind channelization and ventilation potential concerning the prevailing and concerned wind direction, the most feasible built-environment setting can be proposed.

However, for post-construction scenarios (Approach 2 in Figure 3), thorough demolition and evacuation remains only alternative if the risks from industrial-residential land-use conflict turn high; while careful planning and rational demolition-retention approach can be adopted in a low risk context. Nevertheless, in-situ adaptions are recommended post-assessment of wind channelization and ventilation potential of possible alternate scenarios.

In bringing together urban morphology and environmental analysis, the methodology applied in this study recommends few proposals that would make residential development in peripheral, highly polluting industrial zones more liveable and healthy. These range from extensive preparatory assessments in the early design stage to in-situ adaptions that would improve airflow and ventilation within existing buildings. 

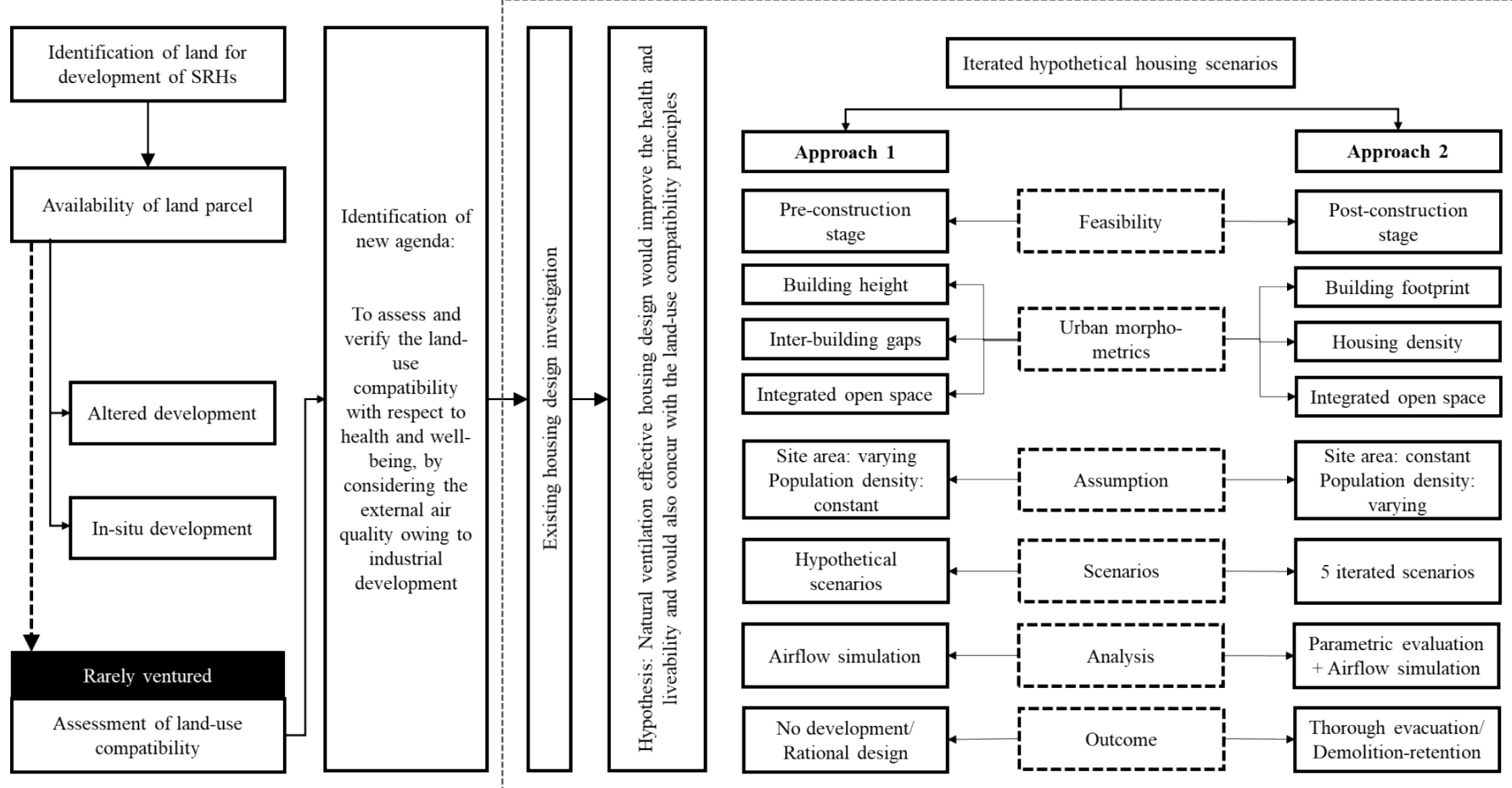

Figure 3 Methodology adopted in the study. 
The commercial CFD code ANSYS FLUENT v16.2 was used to perform the simulations. The computational domain dimensions were prepared based on the best practice AIJ guidelines by Tominaga et al., (2008). The height of the domain was kept 144m for Natwar Parekh and Mahul SRH colony conforming to 6 times the maximum building height. The domain boundaries were kept to a distance of $360 \mathrm{~m}$ with reference to 15 times the maximum building height, to consider different approaching airflow directions. The computational grid was created, resulting in a tetrahedral mesh of 897,737 cells for Natwar Parekh and 6, 379,459 cells for Mahul SRH colony with a minimum of 25 cells on the building corners and walls. For deducting the computational cost, the geometry of the housing complexes was abridged with an accuracy of $1 \mathrm{~m}$, while particulars like balconies, windows and other details were neglected.

Uncertainties associated with natural ventilation including stochastic nature of local wind conditions and obstacles in the airflow path makes it difficult to estimate natural ventilation numerically. This study adopted a deterministic simulation approach while accounting the natural ventilation linked unreliability. The models were well-mixed using double precision, three dimensional, parallel, and finite volume pressure-based solver.

The steady-state Reynolds-Averaged Navier-Stokes (RANS) equations were solved in combination with standard $\mathrm{k}-\varepsilon$ turbulence model. Here $\mathrm{k}$ is the turbulent kinetic energy $\left(\mathrm{m}^{2} / \mathrm{s}^{2}\right)$, and $\varepsilon$ is dissipation rate $\left(\mathrm{m}^{2} / \mathrm{s}^{3}\right)$ of the fluid, here wind. It is a two-equation model, with a general description of turbulent properties of flow provided employing two transport equations. The turbulent fluid is initially presented as a laminar flow, with higher viscosity, next the turbulent motion-related differential equations are estimated, from which the micro-level higher viscosity values are calculated. The Semi-Implicit Method for Pressure-Linked Equations (SIMPLE) algorithm and second-order UPWIND discretisation method were used for coupling pressure-velocity equations and discretising the convection term in the governing equations respectively. The simulations used hybrid initialization with minimum 10,000 iterations to achieve convergence. Along with the justification of the grid independence test, the solution was considered to converge till $10^{-6}$ (RMS) of the residuals of the air velocity profile in all the simulated models. The wind-related data collected from the Indian Meteorological Department (IMD) Mumbai were utilised as boundary conditions for the CFD simulations. The general boundary conditions, generated following the AIJ guidelines are presented in Table 1.

Table 1 General boundary conditions for site-based airflow CFD simulations in ANSYS.

\begin{tabular}{ll}
\hline Model Classification & Method \\
\hline Solver & $\begin{array}{l}\text { Segregated solver; 3D steady-state; First-order Implicit form; Finite } \\
\text { Volume Solver; Absolute velocity formation }\end{array}$ \\
$\begin{array}{l}\text { Energy Equation } \\
\text { Viscous Model }\end{array}$ & $\begin{array}{l}\text { Standard k- } \varepsilon \text { turbulence model; Standard Wall Function; Full Buoyancy } \\
\text { effects }\end{array}$ \\
Computational & $\begin{array}{l}5 \mathrm{H} \text { (inlet and lateral sides), 15H (outlet), 7H (top) (where H represents the } \\
\text { height of the building) }\end{array}$ \\
Domain & $\begin{array}{l}2.5 \mathrm{~m} / \mathrm{sec} \text { (IMD Mumbai) } \\
\text { Inlet air velocity }\end{array}$ \\
$\begin{array}{l}\text { Discretisation method } \\
\text { Pressure-Velocity }\end{array}$ & $\begin{array}{l}\text { SIMPLE (Semi Implicit Method for pressure linked equations) } \\
\text { coupling algorithm } \\
\text { Convergence criteria }\end{array}$ \\
\hline
\end{tabular}


374 Owing to the challenges concerning land-use compatibility at post-construction scenario, where alteration of building disposition using well-established built-environment metrics becomes unmanageable; the only degree of freedom includes demolition of affected buildings and reducing the victim population density. Figure 2 illustrates that the refinery is located at the eastern side of the Mahul SRH colony, while according to Indian Meteorological Department (IMD) Mumbai, predominant wind direction remains east for three to four months annually. In the case of the annual effect of high pollution levels from the adjacent refinery, thorough demolition would have been the only alternative. However, owing to seasonal or quarterly impacts as observed in Mahul SRH colony, partial demolition and conservation was selected as the optimal approach. Hence, considering the current wind-pattern and building density as the major metrics, six hypothetical scenarios were generated.

A criteria-based scenario generation framework was applied here to create the base-case and five hypothetical iterated urban built-forms (Scenario 1 to Scenario 5) as elucidated in Figure 4. The following criteria included were:

i) Building blocks should be removed in such a way that the consequential building disposition enables wind channelization within urban fabric through air-path creation (Edward Ng, 2010).

ii) Built-forms should be removed in a way that increases the number of buildings' front facades facing open spaces.

iii) Building blocks should be removed such that the open spaces are interconnected.

iv) Building blocks should be removed in a way such that the density is gradually reduced.
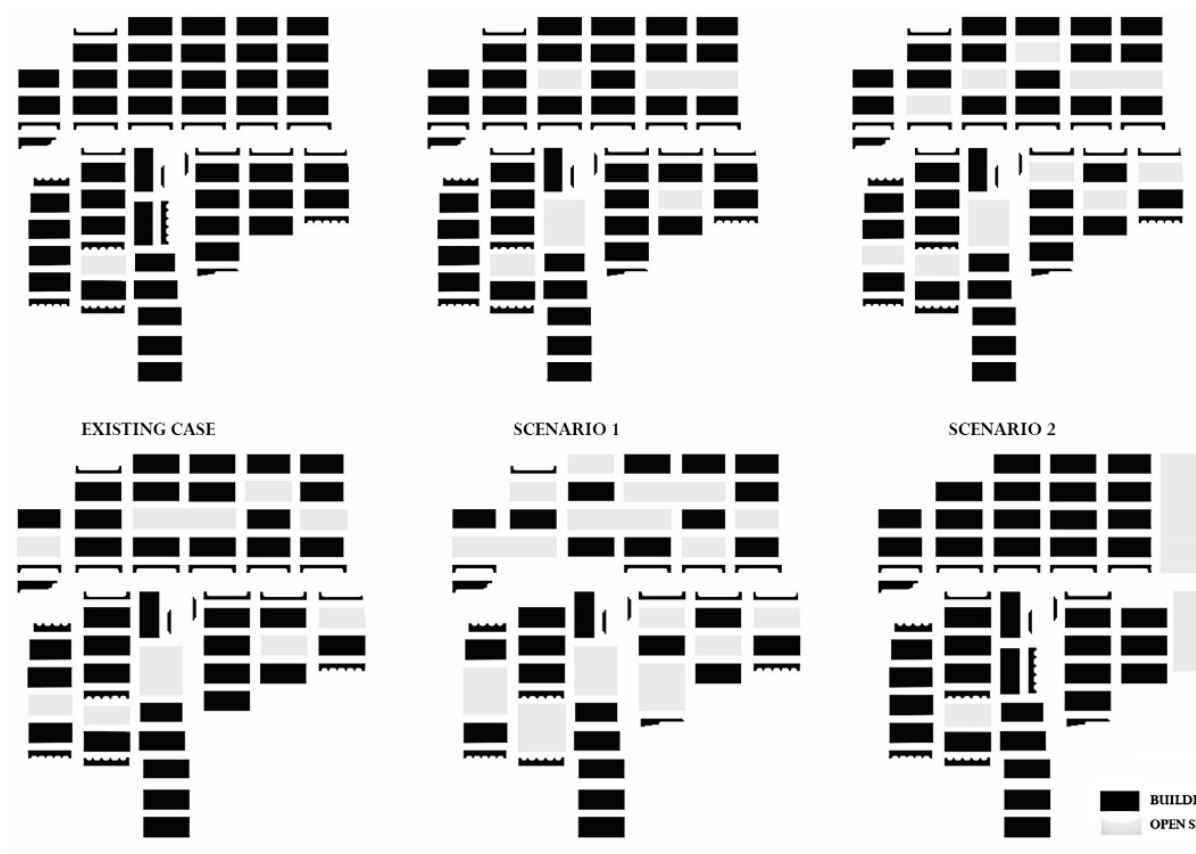

SCENARIO 3

SCENARIO 4

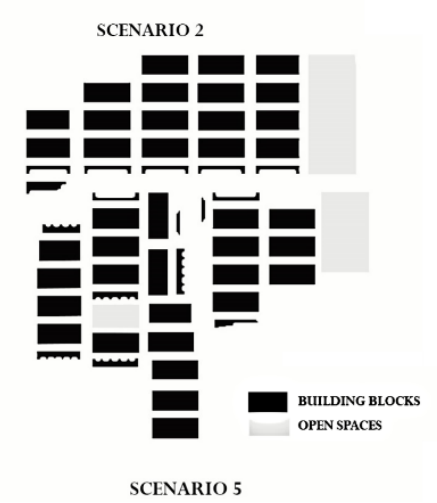

Figure 4 Iterated Urban built-forms modelled for Mahul SRH colony.

Figure 4 elucidates that Scenario 1 to 4 were generated following the afore-mentioned criteria. However, Scenario 5 was formulated as a different controlled group alternative where only the affected building blocks on the eastern side of the site were removed, thus reducing the density. In Scenario 5, the other criteria and building arrangement remained constant. This approach was adopted, as a 
408

comparison between the controlled alternative and other scenarios would aid in understanding the impact of morpho-metrics and building arrangement on site-based airflow distribution.

Hence, this section presents major urban morpho-metrics like density, building area, inter-building distance and integrated open-spaces and highlights urban morphology analyses-related notions to couple them with aerodynamic reflections (see Table 2). In this approach, the population or number of apartments were varied while the site area remained constant.

Table 2 Urban morpho-metric indicators used for parametric evaluation.

\begin{tabular}{ll}
\hline Spatial variables & Description \\
\hline $\begin{array}{l}\text { Site Coverage (SC) } \\
\text { Number of Building blocks }\end{array}$ & $\begin{array}{l}\text { Total site area }\left(\mathrm{m}^{2}\right) \\
\text { The number of building blocks in the site. }\end{array}$ \\
$\begin{array}{l}\text { Building Footprint (BF) } \\
\text { Social interaction space }\end{array}$ & $\begin{array}{l}\text { The area of building in a site. } \\
\text { Amount of social interaction space or positive space within the site } \\
\text { which can be utilised as community ground, play areas etc. } \\
\text { Ratio of positive to } \\
\text { negative space (PN) }\end{array}$ \\
$\begin{array}{l}\text { Rise in open space does not essentially decipher that space has a } \\
\text { proper utilisation, i.e. positively influence on the residents, or has a } \\
\text { functional advantage. These spaces are often termed as spaces left } \\
\text { over after planning (SLOAP) or negative space. } \\
\text { Estimated by associating the total population in the urban area to the } \\
\text { total site area. }\end{array}$ \\
\hline
\end{tabular}

\section{Results}

\subsection{Simulation of outdoor ventilation of the existing scenario}

The site-based airflow analysis around the buildings with an ambient air velocity of $2.5 \mathrm{~m} / \mathrm{sec}$ is illustrated in Figure 5. The 'dark blue' $(0.00-0.66 \mathrm{~m} / \mathrm{sec})$ bands infer that natural ventilation is insufficient to promote thermal comfort in the living spaces through cross-ventilation. While the 'yellow' to 'red' $(2.20-3.52 \mathrm{~m} / \mathrm{sec})$ bands infer that high naturally-driven wind velocity would be able to deliver thermal comfort and high air exchange rates without the aid of any electro-mechanical cooling devices-(Bardhan et al., 2018) (Bardhan, Debnath, Malik, \& Sarkar, 2018).

The housing layout of Natwar Parekh colony allows cross-ventilation within the buildings, with air velocity ranging between $1.10-2.42 \mathrm{~m} / \mathrm{sec}$ along the building structures. The orientation of buildings concerning prevalent wind direction allowed the formation of air-paths thus increasing wind channelization effects. This flow is defined by separation at obstacle edges and the formation of reattachment and recirculation phenomenon upwind, on the sides and downwind the obstacles, which increase turbulence. Since the tenement windows face along the structure, turbulence and cross flow modify the ventilation potential, and recirculation phenomena with span-wise flow develop behind each building facets, thus increasing airflow potential. 

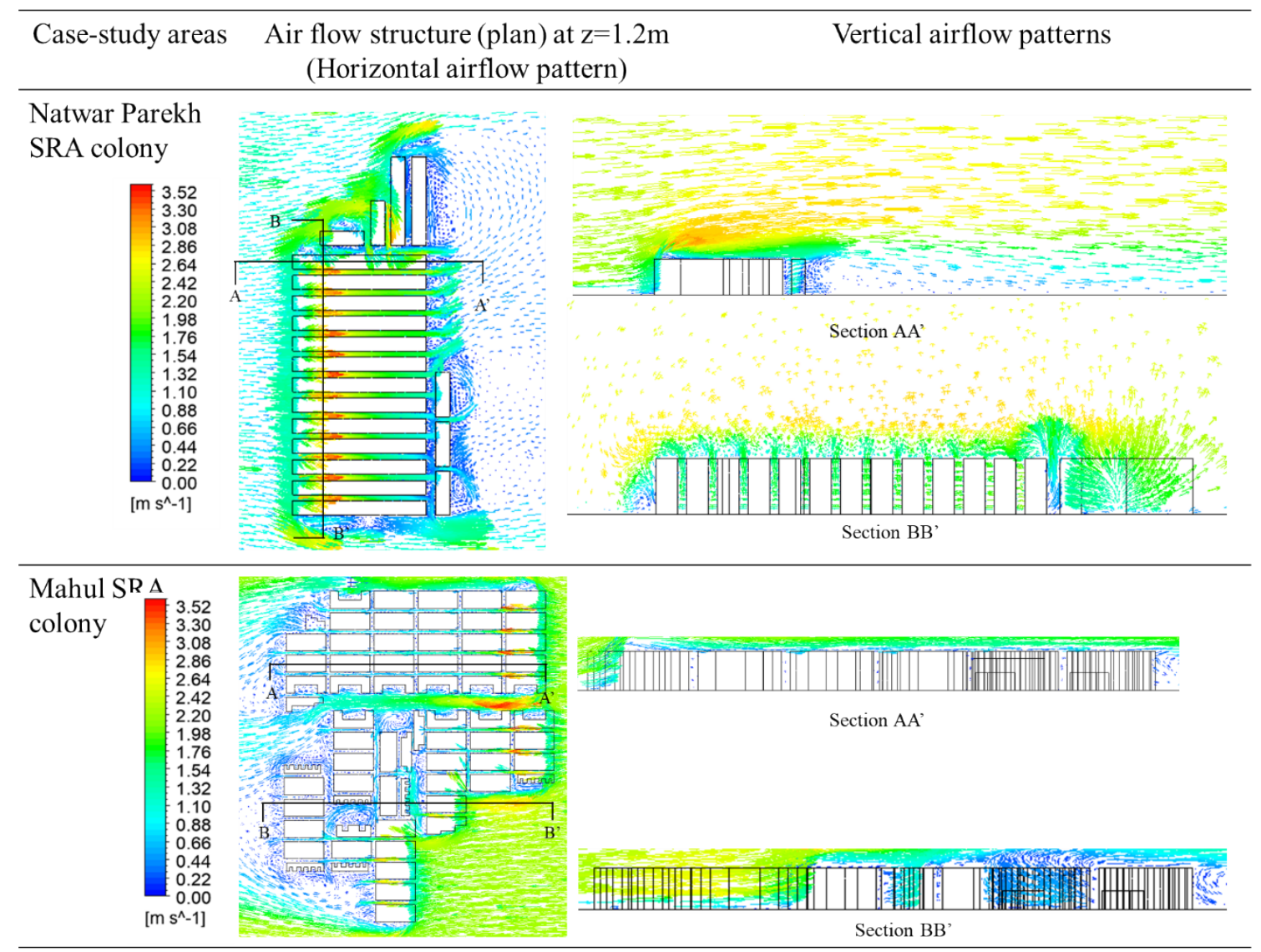

Figure 5 Site-based external airflow simulations for base-case scenarios (Authors' computation and

However, a relatively lower range of air velocity (blue colour bands) was observed between the building blocks for Mahul SRH colony, deducing high probability of inferior air exchange rates and deteriorated cross-ventilation effectiveness throughout the site. The CFD simulated average air velocity for Natwar Parekh was recorded $1.54 \mathrm{~m} / \mathrm{sec}$, while it ranged as low between $0-0.22 \mathrm{~m} / \mathrm{sec}$ for the Mahul SRH colony, which advertently leads to poor airflow. Furthermore, the low airflow zones were found consistent irrespective of height, representing that the built-environment design itself obstructs and controls the airflow throughout. The poor airflow characteristics in Mahul SRH colony as shown in Figure 5 is due tocan be attributed to the eompactly arrangedhyper-dense talltowering and bulkyand huge buildings structures with minimum low intra-building distancegaps. Yuan \& Ng, (2012) in their study on Hong Kong identified that densely compactly packed buildings-built-volumes escalate the incoming wind resistance and obstructhinder the air penetration within the urban fabric through skimming airflow regime. The tightconstricted narrow streets-side alleys in Mahul colony with tall towering structures built-volumes on both either sides-ways result in the formation ofadvertently develop deep urban-canyon with $\mathrm{H} / \mathrm{W}$ ratio of 8.33 for $3 \mathrm{~m}$ wide alleys and 6.25 for $4 \mathrm{~m}$ wide alleys, substantially higher thanfar exceeding the prescribed recommended value of 0.7 as peraccording to the Oke's law. Edward Ng, (2010) also suggested building width to be three times the height and ten times the length length for enhanced air channelization. to be three and ten times the width respectively. But, Mahul SRH had length, width and height of $57.74 \mathrm{~m}, 27.92 \mathrm{~m}$ and $25 \mathrm{~m}$ which obstructed the air pathchannel. The Hong Kong based Team Clean Final Report of Hong Kong suggested that absence of wind channels, compact tall and bulkycompactly arranged huge and towering built volumes, narrow constricted street-alleys, the dearth of integrated open spaces and insufficient-inadequate air paths deteriorated degraded the urban ventilation which led to thermal discomfort-_and incidence of Severe 
Acute Respiratory Syndrome (SARS) in Hong Kong in 2003. With compactly arranged high-rise buildings in the upstream zone and devoid of any integrated large open-to-sky space, the whole site exhibited lower ventilation potential because of the skimming wind flow regime. Though the obstacle dimensions and geometry in Mahul SRH colony affected the cavity zone length and aided in forming additional recirculation phenomena in the building corners and niches, low air velocities persisted between obstacles and channel flows. However, the problem gets inflated as Mahul SRH colony, located adjacent to the polluting refinery, gets affected by the degraded air quality with stale polluted air and extremely low pollutant transport rate.

\subsection{Simulation of outdoor ventilation of iterated scenarios}

The airflow simulations of the iterated scenarios are demonstrated in Table 3. This section determines how natural ventilation and site-based airflow distribution is varying depending on the morpho-metrics of number of buildings, building footprint, integrated open space and housing density.

\section{Number of building blocks (NB)}

In this study, the number of building blocks (NB) referred to the number of built-volumes present on the site. As the built-volumes were eliminated, the number of building blocks within the site reduced from 68 to 45 in the iterated scenarios. With the elimination of the building blocks, while keeping the site area constant, the air channelling paths within the site turned more efficient. Due to the lesser number of built-volumes, the aspect ratio also decreased to 2.02, noticeably less than the existing case (6.25-8.33). Parametric studies on wind flow and environmental simulations showcase that secondary and weaker wind vortexes tend to develop if aspect ratio becomes more than 2 (Edward Ng., 2010) (See Figure 6b). Elimination of building blocks leading to increase of open spaces and lower canyon ratio escalated the site-based airflow distribution from $0.22 \mathrm{~m} / \mathrm{sec}$ for the existing case to $1.68 \mathrm{~m} / \mathrm{sec}$ for scenario 5 through breakage, reattachment and recirculation phenomenon. However, it can be observed from Table 3 that for Scenario 1 and Scenario 2 where only 6 and 10 built-volumes were removed, the air-paths were not prominent. Whereas for Scenario 3 and Scenario 4, where 12 and 23 building blocks were removed from the site, higher site porosity led to the formation of three distinct effective air-paths, which would advertently increase the polluted air disposal rate.

However, the controlled alternative of Scenario 5 with 10 built-volumes removed, performed poor in terms of ventilation potential than other scenarios (average velocity: $0.22 \mathrm{~m} / \mathrm{sec}$ ), thereby establishing that sole removal of building blocks would not aid in improving the site-based ventilation rate. Whereas, careful and rational built-volume elimination by following architect Charles Correa's principles of 'a series of flowing open-to-sky spaces' mentioned in his book 'The new landscape' would lead to efficient site-based ventilation at a neighbourhood scale (Charles Correa, 1988).

Jane Jacobs while stating that 'urban renewal/slum clearance never looked at the needs of city-dwellers' had argued that 'buildings should be positioned to provide natural surveillance of the street' (Jacobs, 1961). However, with the decrease in urban canyon ratios in the hypothetical scenarios, the rationally designed urban morphology would now be capable of providing natural surveillance thus complying with the theories of 'Broken window' and 'Defensible space' as well.

\section{Building Footprint (BF)}

The morpho-metric of building footprint (BF), similar to NB offers a measurement of the total area of built volume in the site and ranges from 0 to 1 , where the value of 'one' refers to the context where the whole site is fully occupied by building forms. Table 3 demonstrates that the building footprint gradually decreased from 0.59 for the base-case scenario to $0.53,0.49,0.48$ and 0.37 for Scenarios 1 to 4 with the gradual removal of built-volumes. With the decrease in building footprint, the amount of 
open spaces within the site gradually increased. Hence, an increase in site-based ventilation rate was noticed.

\section{Positive to Negative Space (PN)}

In this study, positive space refers to the large open spaces formed by eliminating the built-volumes from the site which can be utilized for social interaction, whereas the narrow unutilized inter-building alleys were considered as the 'negative' (Azhar \& Gjerde, 2016; Carmona, 2010), disconnected and 'non-community' spaces (S. J. Lee, Hwang, \& Lee, 2015) or spaces left over after planning (SLOAP) (Bardhan, Debnath, Malik, \& Sarkar, 2018). The ratio of positive to negative space has been utilized as another morpho-metric for determining ventilation potential. The value below 'one' indicates a higher amount of negative space, while the value more than 'one' refers to higher amount of positive space within the site. Ventilation principles and wind flow regime as shown in Figure 6a elucidates that while narrow negative spaces lack airflow through skimming flow regime, the wide positive spaces experience improved ventilation potential through isolated roughness and wake-interference flow regime. Table 3 demonstrates that while the amount of negative space was higher than that of the positive space in existing case (P/N: 0.14), the ratio increased to 1.18 for Scenario 1. Subjective interpretation of this phenomenon elucidates that removal of 6 built-volumes from site increased the amount of positive open spaces, thereby increasing $\mathrm{P} / \mathrm{N}$ ratio more than 1 for the Scenario 1 . Similarly, the P/N ratio gradually increased for Scenario 2 (2.13), Scenario 3 (2.39) and Scenario 4 (6.95). While the average air velocity over the existing scenario was $0.22 \mathrm{~m} / \mathrm{sec}$, it increased to $0.77-1.68 \mathrm{~m} / \mathrm{sec}$ for the hypothetical scenarios. This can be attributed to the creation of voids within the urban built-environment which aided in increasing airflow through high velocity wind vortex formation.

However, it can also be observed from Table 3 that despite 10 built-volumes were eliminated from the controlled alternative of Scenario 5, the positive to negative space ratio remained 1.43, less than that of Scenario $2(\mathrm{P} / \mathrm{N}: 2.13)$ with the same number of removed buildings. This resulted in poor airflow performance over the site, even with $\mathrm{P} / \mathrm{N}$ value of more than 'one'. This can be attributed to the fact that although 10 buildings were removed, it did not impact the rest of building disposition pattern of the site and failed to create large integrated open areas or positive space, thereby minimizing the reduction of negative spaces.

(a)

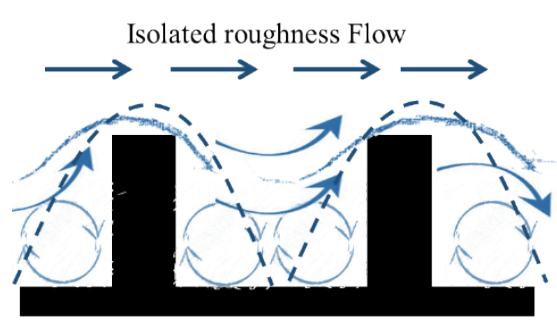

Secondary wind vortex
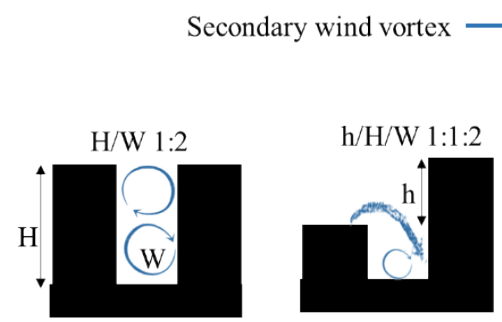

522

Figure 6 (a) Patterns of airflow regime based on the urban canyon, (b) wind flow based on canyon ratio (Adapted from Edward Ng., 2010).

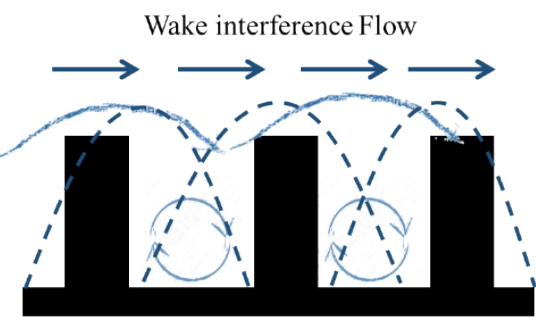

(b)
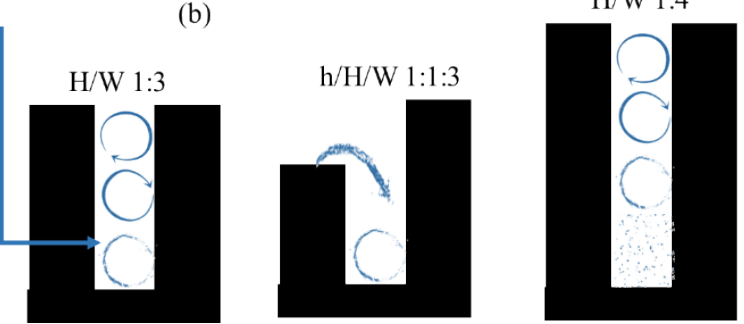

$\mathrm{h} / \mathrm{H} / \mathrm{W} 1: 1: 4$

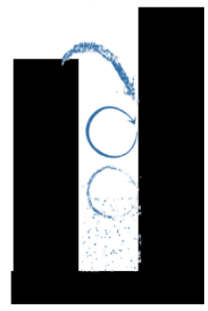

Skimming Flow

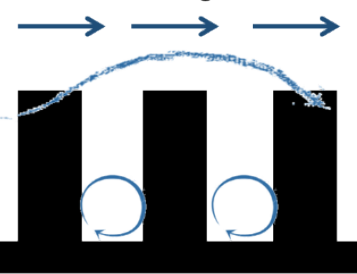

H/W $1: 4$

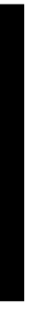


The morphological indicator of social interaction space (SIS), in the similar notion of that of positive to negative space, is defined as the ratio of the amount of positive space to the total site area. The value of SIS would range from 0 to 1 where the value 'zero' refers to the absence of any positive social interaction space, and the value 'one' refers to maximum possible positive open space. Absence of any integrated large open space led to the SIS value of 0.01 for the existing case. On the other hand, with the gradual removal of $6,10,12$, and 23 building blocks, the amount of large positive open space increased thereby increasing the SIS value from 0.01 to $0.08,0.13,0.14$, and 0.25 respectively from Scenario 1 to Scenario 4. These open spaces acting as breathing zones aided in the formation of air paths with increased polluted air disposal rates.

535 However, similar to $\mathrm{P} / \mathrm{N}$ indicator, Table 3 shows that despite the removal of 10 built-volumes from the 536 controlled alternative of Scenario 5, the SIS remained as low as 0.11, less than that of Scenario 2 (SIS: 5370.13 ) with the same number of removed buildings.

538 Wilmsen, Adjartey, \& Hulten, (2019) had contested that the IRR model focuses only on materialistic 539 up-gradation while failing to illuminate on the social liveability parameters of the displaced population. 540 However, the presence of adequate positive and social interaction space in these rehabilitated sites would not only improve the micro-climate and health condition but would also integrate a sense of community interaction and social cohesion thereby, upgrading the social organisation among the disadvantaged population.

\section{$544 \quad$ Housing Density (HD)}

The morpho-metric of housing density is defined as the number of dwelling units per unit hectare of

546 site area and is expressed as Dwelling Unit (DU)/ Hectare(Ha) i.e. DU/Ha. Here, the existing layout of Mahul SRH colony with a current density of 1327 DU/Ha was reduced gradually by removing the building blocks to comply with the building codes and design guidelines (National Building Code of India: 500DU/Ha and Greater Mumbai Development Control Regulations: $200 \mathrm{DU} / \mathrm{Ha}$ ). Five iterative scenarios were generated with a density of $1000 \mathrm{DU} / \mathrm{Ha}$ (Scenario 1), $800 \mathrm{DU} / \mathrm{Ha}$ (Scenario 3), two 650 DU/Ha (Scenario 2 and Scenario 5), and $500 \mathrm{DU} / \mathrm{Ha}$ (Scenario 4). It can be observed from Table 3 that Scenarios 1 to 4 exhibited high air velocity zones. Although Scenario 1 with reduced density of 1000DU/Ha had higher occurrences of red-orange colour bands, the air channelling or pollutant transport paths were still not prominent, which could degrade the ventilation performance. Nevertheless, the flow field was observed to be heterogeneous at pedestrian-level and highly affected by building density differences for Scenario 3 with density 800DU/Ha. The other characteristic of flow in open squares or street intersections showed higher mean and turbulent velocities $(1.38-1.53 \mathrm{~m} / \mathrm{sec})$. Scenario 4 with 500DU/Ha density performed superior among all the alternatives in terms of ventilation rates and airflow with an average air velocity of $1.68 \mathrm{~m} / \mathrm{sec}$. Despite Scenario 2 and controlled alternative of Scenario 5 had similar density (650 DU/Ha), better ventilation performance with effective air-paths was observed for Scenario 2 owing to the judicious creation of ventilation corridors or air 562 paths.

This phenomenon establishes that architects and urban planners should necessarily connect the 564 morphological variable of urban density with the urban design concept of 'connectedness of spaces' as recommended by architect Charles Correa to design climate-sensitive housing layouts (Charles Correa, 88). Even with higher density Scenario 3 (800 DU/Ha) also performed better than Scenario 2 (650 $567 \mathrm{DU} / \mathrm{Ha}$ ) in terms of 'social interaction space' and 'positive to negative space'. Subjective explanation 568 of these designs exhibits that the present alignment of the SRH Township intrinsically blocks wind569 flows crossways, while other scenarios deliver improved cross-ventilation conditions. Although 570 Scenario 4 displays additional extent of higher velocity zones across the buildings, considering the 571 current urbanization trend, population density as well as the efficiency of airflow across the buildings 
572 and formation of cross-ventilation air paths, Scenario 3 with 800DU/Ha can be considered as optimised 573 built-form for Mahul SRH that can promote better pollutant dispersion rate and higher indoor air quality 574 as well. With improvement in site-based ventilation potential, the pollution disposal rate would increase 575 by increasing air change rate. Consequently, the pollution from refinery reaching the site would be 576 removed at a faster rate, thereby minimising its health-related impact on retained inhabitants.

577 Additionally, the built-environment design with a rational spatial disposition and environmental setup 578 would also improve the health and liveability of displaced population, thus concurring with the theories 579 of 'Maslow's pyramid of needs', 'Mercer Quality of Living Indicators', 'Lefebvre's production of 580 social space' and 'SUBETs planning tools'. 
Table 3 Parametric evaluation and site-based airflow analysis of the existing case and the iterated scenarios.

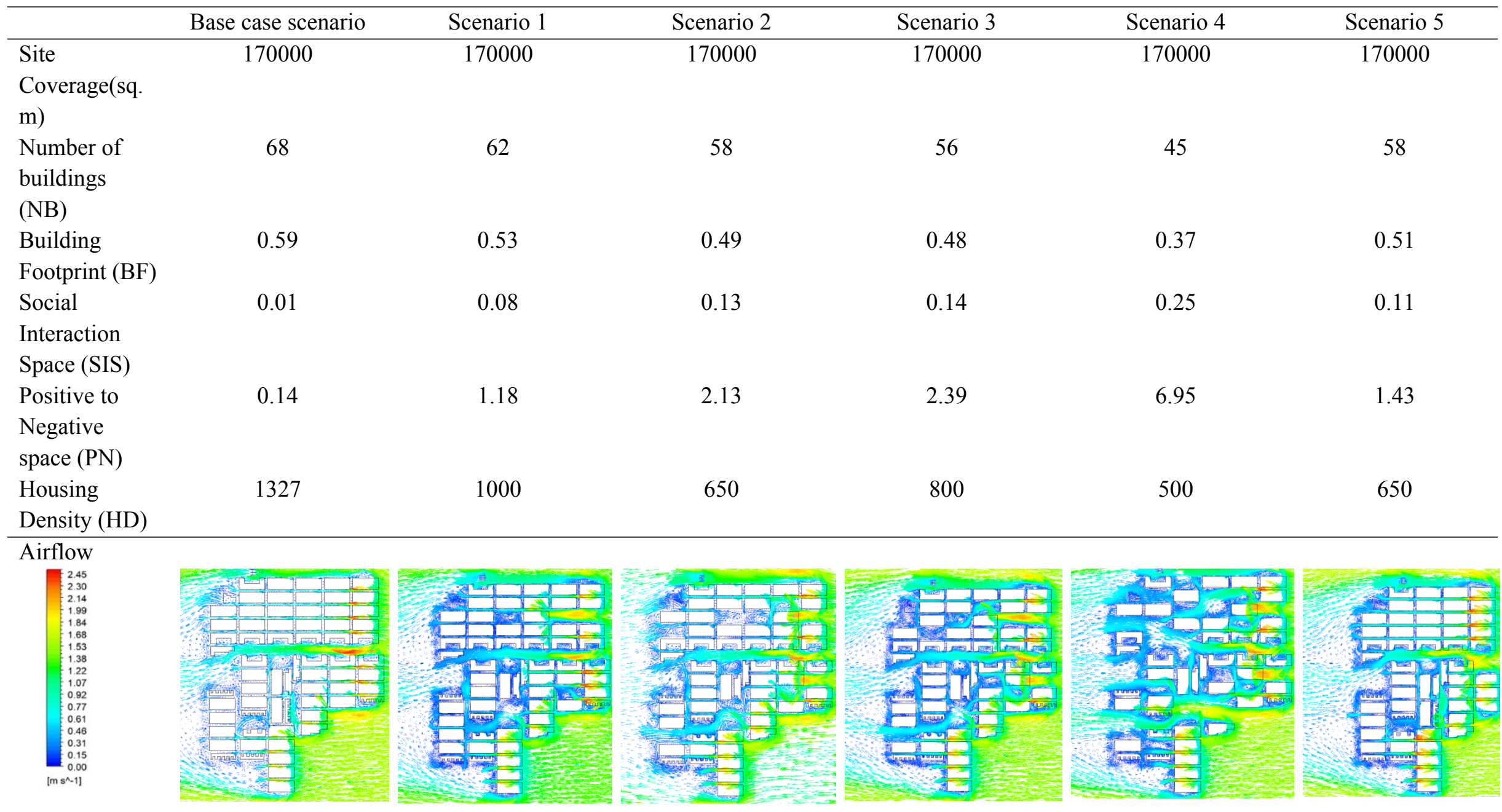

Based on authors' computation and simulation 
584 The paper focuses on the aspect of land use compatibility on the development of mass housing schemes 585 for Lower Income Group (LIG) and Economically Weaker Section (EWS). In this research, there is no 586 differentiation made among who should be occupying in those housing such as a) people already 587 inhabiting the site, b) within neighbourhood or c) people relocated from other parts of the city or/and 588 d) even if these apartments are put on sale at market prices. While relocation has its own drawbacks 589 such as loss of job, disruption of social network, inadequacies of social infrastructures and importantly 590 access to street (Michael M. Cernea, 1995; Jones, 2017; Sholihah \& Shaojun, 2018), this research argues 591 that selection of sites that affirm with the security of health aspects should be maintained with utmost 592 diligence.

593 Despite traditional land-use planning theories follow restricted zoning laws, consequently parcelling 594 conflicting land-uses distantly; this study by treating currently urbanising cities as a socio-ecological 595 system investigates into an optimum solution where conflicting land-uses can coexist after careful 596 planning and management. By cultivating the interlinkage between urban morphology and 597 environmental planning, this study introduces environmental analysis as an evaluation tool and 598 morphological indicator-based habitat planning proposals as criteria for testing the micro-level land599 use compatibility. While land use incompatibility assessment concerning air pollution regulations has 600 been widely researched and contested, the methods of land use compatibility testing tools especially for 601 determining micro-level effect of incompatible land-use zoning on local level air quality remains an 602 elusive concept. Furthermore, land use compatibility with respect to health and liveability aspect has 603 been studied a few times. This study is, therefore, an initial approach in deriving a system-driven tool 604 for land use compatibility assessment at micro-scale, particularly from the health and liveability 605 perspective, specifically for high rise, high-density low-income housings, where indoor mechanical air606 conditioning may be a luxury.

607 In metro-cities, the challenge of land-use incongruity upsurges when habitation in infeasible land use 608 adjacency distresses health and liveability of the inhabitants. In Mumbai, government authorities, while 609 developing low-cost mass housing, compellingly converted an atomic research centre marked special 610 industrial land use, initially kept for industrial security, to 'residential' land use. Subsequently, the 611 tenements in Mahul, close to the refinery, gradually were exposed to the deteriorated quality of air with 612 benchmark exceeding concentrations of pollutants like Volatile Organic Compounds (VOCs) especially 613 nickel and Benzo Pyrene-(Maharashtra Pollution Control Board (MPCB) Mumbai, 2016)(Shroff, Rav, 614 \& Pathak, 2019). Technical reports on the health status of Mahul residents revealed a higher incidence 615 of skin diseases and upper respiratory problems within three years after shifting to the slum 616 rehabilitation units.

617 Interestingly, Mahul colony was surrounded by chemical factories, industrial belts, commercial and 618 retail areas and health facilities generating job opportunities, therefore eradicating the key-aspects and 619 risks of joblessness, homelessness, health insecurity that lead to the impoverishment of the displaced as 620 explained by Cernea's IRR model (Cernea, 1997; Michael M. Cernea, 1995). Yet, this scheme failed at 621 Mahul since the residents determined to leave the mass housing majorly for health issues and not regular 622 socio-economic problems. Poor health cropping up from deteriorated air quality among many other causes eventually compelled the residents to vehemently drive for vacating the rehabs and shift elsewhere.

625 This study takes up the challenge in this precarious situation and attempts to deliver a systematic 626 approach based methodology, which would promote improved liveability to the disadvantaged 627 population. Taking infeasible land use aggregation as an unescapable phenomenon, this study aimed to 
examine the severity of the local level residential-industrial land-use conflicts. Unlike typical land-use planning researches, this study promoted a diagnostic approach applicable both at early design stages and for rarely ventured but significant post-construction phase considering airflow as a measurement strategy. While this analytical reminiscent approach at pre-construction stage would aid in rectifying the inaccuracies in initial land-use zoning and inhibit the erroneous displacement of the population; it also becomes inevitable at post-construction stage, where optimal habitat planning evolved through land use compatibility testing would aid in delivering improved residential liveability.

While the low-income mass housings especially the slum rehabilitated colonies in Mumbai are placed in diverse settings, few turns detrimental. Hence, this study compared the liveability challenges, owing to poor air quality, raising from inaccurate land-use zoning for two case studies at varying ecological set-up. While Natwar Parekh colony was located in an appropriate residential land use, surrounded by low-rise residential zones; Mahul colony was the affected one. Therefore, this study utilised Computational Fluid Dynamics (CFD) for testing the land use compatibility of these LIG housing. It was reckoned that Natwar Parekh colony performed better in terms of air flow. This evinces the fact that not only the built-environment design but also the compatible land use would allow better external urban microclimate, and enhanced liveability. However, deteriorated ventilation effectiveness was observed for Mahul SRH, where poor site-based air flow indicated stagnancy of air between the buildings, further reducing the pollutant transport rate (Figure 5). Mahul SRH Township was additionally suffering from external pollution sourced from petroleum refinery induced combustion activities. This indicates that while retaining the adjacency of polluted industrial development, careful built-environment planning might solve the air pollution issues.

This study, after testing the severity of land-use incompatibility suggested rational demolition-retention of built-volumes as an optimal mitigation strategy. Here we hypothesized that 'better liveability can be achieved through improved urban micro-climate, which can be promoted through efficient site-based natural ventilation; which in turn is a subject of land-use compatibility and built-environment design.' Considering housing density as a primary examining indicator, and amount of voids, number of building blocks as other well-established morpho-metrics (An et al., 2019; Asfour \& Gadi, 2007;-Cheung \& Liu, 2011; Zhang, Gao, \& Zhang, 2005), this study generated hypothetical iterated scenarios by altering the building blocks arrangement and built-density quotient. However, wise and rational elimination approach, involving the consideration of urban design's 'flow of open-to-sky space' related principles become necessary.

Table 3 elucidated that with gradual decrease in built-volumes, the site porosity increased, thereby increasing the amount of open space. This consequently decreased the urban canyon ratio to 2.02 from 8.33 (existing case) and increased the positive to negative space ratio to 2.39 and 6.95 for Scenario 3 and Scenario 4 respectively from 0.14 (existing case). The deep urban canyon in the existing case led to the formation of weaker secondary wind vortexes, which advertently obstructed the airflow within the urban fabric (Figure 6). Also, CFD simulations elucidated that while the existing case devoid of an integrated open space and high housing density (1327 DU/Ha) exhibited inefficient air velocity (0$0.22 \mathrm{~m} / \mathrm{sec}$ ) through skimming flow regime, Scenario 1 to Scenario 4 with reduced density, adequate integrated open spaces and shallow urban canyons exhibited increased air velocity of $0.77-1.68 \mathrm{~m} / \mathrm{sec}$ by experiencing isolated roughness and wake interference airflow regime. When the urban spatial variable of density was examined, Scenario 2 and Scenario 3 with $650 \mathrm{DU} / \mathrm{Ha}$ and $800 \mathrm{DU} / \mathrm{Ha}$ performed better in terms of airflow than the controlled group alternative Scenario 5 with $650 \mathrm{DU} / \mathrm{Ha}$. This can be attributed to the rational morpho-metric-based built-volume arrangement which assisted in generation of air channelling and distinct pollutant transport paths. This complexity of the urban structure and voids enhance air mixing due to the formation and unification of different vertical and 

judicious removal of building blocks (Ramponi \& Blockenet al.,2 2015z).

However, this study utilised this air channelizing paths and introduced the notion that if the urban morphology is judiciously designed such that the residual built-volumes' position avoid the prevalent direction of incoming wind plume from the refinery, the pollution transfer would get less obstructed, thereby increasing the ventilation and polluted air transport rate.

\section{Conclusion}

682

This study develops a pluri-disciplinary approach to emphasize the necessity of land use compatibility testing to avoid inaccuracies in land parcelling and zoning, which can otherwise impact health security at large. This study, treating cities as a socio-ecological system, brings together urban morphology and environmental planning analysis and recommends certain proposals that would promote healthy and liveable environment in LIG residential zones sharing adjacency with industrial belts. These vary from planning assessments in the early design stage to retrofitting adaptions at post construction stage that would improve airflow and ventilation within existing buildings. The set of urban morpho-metrics of number of buildings in a neighbourhood, building footprint, canyon or aspect ratio or inter-building gaps, integrated and interlinked open spaces and greenery and most importantly housing density need to be included in the LIG mass housing design and planning process as a base-line and evaluation criteria for ensuring health and liveability among low-income population. Based on this study, the following recommendations can be proposed:

- Urban canyon is an integrally crucial morpho-metric with aerodynamic potential. While Oke's law prescribes an aspect $(\mathrm{H} / \mathrm{W})$ ratio of 0.7 , this study through environmental simulations preferred an acceptable value of $2(\mathrm{H} / \mathrm{W}=2)$. This implies that the recommended height of the building can be twice of the width of the adjacent alley for better ventilation.

- For high-density cities, one of the most important and useful morphological indicator is building footprint or number of built-volumes in a site or ground coverage ratio. The windtunnel experiments indicate that the average wind velocity ratio gets halved when the ground coverage increases from 10 to 30 per cent (Kubota., 2008). The simulation predicted results derived from this study recommended a relaxed building footprint of 37 to 49 per cent. However, in this case, careful building disposition plays a crucial role. Development should be laid out and oriented to maximise air penetration.

- Spatial porosity and permeability at ground level is also very effective in improving urban ventilation. One of the major indicators include the ratio of positive to negative space, where the prescribed value should at least be equal to 'one'. The CFD predicted results demonstrated that for better air exchange rates and improved ventilation potential, the recommended ratio of positive to negative space might lie in the range of 1.5 to 3 . This implies that an adequate amount of integrated and interlinked open space and greenery, with the maximum number of buildings' front facades facing parklands should be provided in a neighbourhood for better health conditions.

- Open spaces should be interlinked in such a way as to form air paths or breezeways or ventilationer corridors. In this case, the indicator of social interaction space might lie in the range of 0.08 to 0.25 for better ventilation.

- Housing density is another key parameter to be considered while designing mass-scale housing. While best-case suggests a density of $500 \mathrm{DU} / \mathrm{Ha}$ as also recommended by NBCI, housing 
density in current urbanisation trend and land-shortage scenario might go up to 800DU/Ha, provided the building disposition is designed rationally.

If the land-use compatibility can be assessed using environmental planning approaches like CFD and if the afore-mentioned morphological indicator-based recommendations are implemented, the industrialresidential land-use conflict can be eradicated and restricted at the early design stage or even can be minimised at post-construction phase, thereby reducing the risk of population ill-health conditions. The outcomes of the study are policy-specific; however, the recommendations have implications to a larger stakeholder group who are pursuing land use-housing-urbanisation interaction. Recognising the conceptnotion, language and epistemology of the urban morphology and environmental planning interaction provideoffer the architectsbuilding designers, urban planners, and habitat housing policymakers with a parametric coupled simulation-driven approach to the land-use planning procedure for upcoming mass-scale housing. The morpho-metrics analysedinvestigated here are also intendedproposed to better understand the environmental impacts of land-use incompatibility on health and liveability, which remains a blind-spot in current urban planning. While emission density zoning is required from the air pollution side, spatially sensitive planning is also essential from land-use planning perspective. Especially, in cities like Mumbai, where the current government housing authorities face exorbitant financial burden after the failure of LIG mass housing projects, these early compatibility checks implemented in planning policies can prevent further precarious 'rebound' phenomenon.

\section{Limitations}

The methodology involved in this study has only considered air pollution; while other categories of pollution or hazards induced from the polluting industries have not been accounted. One of the plausible reason behind this is adequate safety measures that can effectively counter the hazardous events. Also, in this study, the authors have considered the pollutant levels and concentrations, and medical status reported in other studies from environmental institutes and government hospitals. In-situ experimental measurements have not been conducted in this study. The quantitative recommendations proposed in this study are based on the authors' computations and simulations and are contextual, hence, need further validation.

\section{Acknowledgements}

The material presented in this study is based in part on the work supported by the Ministry of Human Resources Development (MHRD), Government of India (GoI), Grant No: 14MHRD005-and IRCC-IIT Bombay Grant No: 16IRCC561015. Any options, findings, and conclusions or recommendations expressed in this material are those of the authors and do not necessarily reflect the views of the IRCC - IIT Bombay or-MHRD, GoI.

\section{References}

Aboda, C., Mugagga, F., Byakagaba, P., \& Nabanoga, G. (2019). Development Induced Displacement ; A Review of Risks Faced by Communities in Developing Countries. Sociology and Anthropology, 7(2), 100-110. https://doi.org/10.13189/sa.2019.070205

Andersson, Erik., Barthel, Stephen., Borgstrom., Colding, Johan., Elmqvist., Folke, Carl., \& Gren, Asa. (2014). Reconnecting Cities to the Biosphere: Stewardship of Green Infrastructure and Urban Ecosystem Services. AMBIO, 43, 445-453. 10.1007/s13280-014-0506-y.

An, K., Wong, S., \& Fung, J. C. (2019). Exploration of sustainable building morphologies for e ff ective passive pollutant dispersion within compact urban environments. Building and Environment, 148(July 2018), 508-523. https://doi.org/10.1016/j.buildenv.2018.11.030 
Asfour, O. S., \& Gadi, M. B. (2007). A comparison between CFD and Network models for predicting wind-driven ventilation in buildings. Building and Environment, 42(12), 4079-4085. https://doi.org/10.1016/j.buildenv.2006.11.021

Axinn, W. G., \& Ghimire, D. J. (2011). Social organization, population, and land use. AJS; American Journal of Sociology, 117(1), 209-258. https://doi.org/10.1086/661072

Azhar, J., \& Gjerde, M. (2016). Re-Thinking the role of Urban In-Between Spaces. In Architecture Science Association 2016.

Badland, H., Whitzman, C., Lowe, M., Davern, M., Aye, L., Butterworth, I., ... Giles-corti, B. (2014). Urban liveability: Emerging lessons from Australia for exploring the potential for indicators to measure the social determinants of health. Social Science \& Medicine, 111, 64-73. https://doi.org/10.1016/j.socscimed.2014.04.003

Bardhan, R., Debnath, R., Jana, A., \& Norford, L. K. (2018). Investigating the association of healthcare-seeking behavior with the freshness of indoor spaces in low-income tenement housing in Mumbai. Habitat International, 71(September 2017), 156-168. https://doi.org/10.1016/j.habitatint.2017.12.007

Bardhan, R., Debnath, R., Malik, J., \& Sarkar, A. (2018). Low-income housing layouts under socioarchitectural complexities : A parametric study for sustainable slum rehabilitation. Sustainable Cities and Society, 41(August 2017), 126-138. https://doi.org/10.1016/j.scs.2018.04.038

Bardhan, R., Sarkar, S., Jana, A., \& Velaga, N. R. (2015). Mumbai slums since independence : Evaluating the policy outcomes. Habitat International, 50, 1-11. https://doi.org/10.1016/j.habitatint.2015.07.009

Basagaña, X., Rivera, M., Aguilera, I., Agis, D., \& Bouso, L. (2012). Effect of the number of measurement sites on land use regression models in estimating local air pollution. Atmospheric Environment, 54, 634-642. https://doi.org/10.1016/j.atmosenv.2012.01.064

Bellamy, J., \& Foster, J. B. (1999). Marx's Theory of Metabolic Rift : Classical Foundations for Environmental Sociology. American Journal of Sociology, 105(2), 366-405.

Brown, G., Sanders, S., \& Reed, P. (2018). Using public participatory mapping to inform general land use planning and zoning. Landscape and Urban Planning, 177(March), 64-74. https://doi.org/10.1016/j.landurbplan.2018.04.011

Carmona, M. (2010). Contemporary Public Space, Part Two : Classification, 4809. https://doi.org/10.1080/13574801003638111

Cernea, M. (1997). The Risks and Reconstruction Model for Resettling Displaced Populations. World Development, 25(September 1996), 1569-1587.

Chan, I. Y. S., \& Liu, A. M. M. (2018). Effects of neighborhood building density, height, greenspace, and cleanliness on indoor environment and health of building occupants. Building and Environment, 145(June), 213-222. https://doi.org/10.1016/j.buildenv.2018.06.028

Charles Correa. (1988). The New landscape: Urbanisation in the Third World.

Cheung, J. O. P., \& Liu, C. H. (2011). CFD simulations of natural ventilation behaviour in high-rise buildings in regular and staggered arrangements at various spacings. Energy and Buildings, 43(5), 1149-1158. https://doi.org/10.1016/j.enbuild.2010.11.024

Clements-croome, D., Marson, M., Yang, T., \& Alraksinen, M. (2017). Planning and Design Scenarios for Liveable Cities. Encyclopedia of Sustainable Technologies (Vol. 2). Elsevier. https://doi.org/10.1016/B978-0-12-409548-9.10179-4 
rehabilitation : Investigating a rebound phenomenon using a backeasting approach. Habitat International, 87(February), 75-90. https://doi.org/10.1016/j.habitatint.2019.03.010

Douglass, Mike. (1989) The Environmental Sustainability of Development: Coordination, Incentives and Political Will in Land Use Planning for the Jakarta Metropolis. Environmental Sustainability.11(2), 211-238.

Dutton, Spencer M., Banks, Savid., Burnswick, Samuel., \& Fisk, William J. (2013). Health and economic implications of natural ventilation in California offices. Building and Environment (67), 34-45. DOI: 10.1016/j.buildenv.2013.05.002.

Edward Ng. (2010). Designing High Density Cities For Social \& Environmental Sustainability. ISBN: 978-1-84407-460-0.

Govender, T., Barnes, J. M., \& Pieper, C. H. (2011). Housing conditions, sanitation status and associated health risks in selected subsidized low-cost housing settlements in Cape Town, South Africa. Habitat International, 35(2), 335-342. https://doi.org/10.1016/j.habitatint.2010.11.001

Huang, Q., \& Song, W. (2019). A land-use spatial optimum allocation model coupling a multi-agent system with the shuffled frog leaping algorithm. Computers, Environment and Urban Systems, 77(June 2018), 101360. https://doi.org/10.1016/j.compenvurbsys.2019.101360

Jacobs, J. (1961). The Death and Life of Great American Cities.

Jana, A., Bardhan, R., Sarkar, S., \& Kumar, V. (2016). Framework to assess and locate affordable and accessible housing for developing nations : Empirical evidences from Mumbai. Habitat International, 57, 88-99. https://doi.org/10.1016/j.habitatint.2016.07.005

Jones, P. (2017). Formalizing the Informal : Understanding the Position of Informal Settlements and Slums in Sustainable Urbanization Policies and Strategies in Bandung, Indonesia. Sustainability, 9(8), 1436. https://doi.org/10.3390/su9081436

Karimi, A., \& Brown, G. (2017). Assessing multiple approaches for modelling land-use conflict potential from participatory mapping data. Land Use Policy, 67(February), 253-267. https://doi.org/10.1016/j.landusepol.2017.06.004

Kiani, M., Nassiri, P., Hosseini, M., \& Monavari, M. (2014). Assessment of land use compatibility and noise pollution at Imam Khomeini International Airport. Journal of Air Transport Management, 34, 49-56. https://doi.org/10.1016/j.jairtraman.2013.07.009

Kim, K., Yoon, J. Y., Kwon, H. J., Han, J. H., Eek Son, J., Nam, S. W., ... Lee, I. B. (2008). 3-D CFD analysis of relative humidity distribution in greenhouse with a fog cooling system and refrigerative dehumidifiers. Biosystems Engineering, 100(2), 245-255. https://doi.org/10.1016/j.biosystemseng.2008.03.006

Kubota, T., Miura, M., Tominaga, Y., \& Mochida, Akashi. (2008). Wind tunnel tests on the relationship between building density and pedestrian-level wind velocity: Development of guidelines for realizing acceptable wind environment in residential neighbourhoods. Building and Environment, $\underline{43 \text { (10), 1699-1708. https://doi.org/10.1016/j.buildenv.2007.10.015 }}$

Lefebvre, H. (1991). The production of space. Malden, MA: Blackwell. Original work published in 1974.

Lueker, J., Bardhan, R., Sarkar, A., \& Norford, L. K. (2020). Indoor air quality among Mumbai's resettled populations: Comparing Dharavi slum to nearby rehabilitation sites. Building and Environment, 167. https://doi.org/https://doi.org/10.1016/j.buildenv.2019.106419

Li, Hw., Lu, Juan., \& Li, Bin. (2020). Does pollution-intensive industrial agglomeration increase residents' health expenditure? Sustainable Cities and Society. DOI:https://doi.org/10.1016/j.scs.2020.102092. 
Ma, Y., Jiang, Y., \& Li, L. (2015). Numerical Simulation of PM2.5 Distribution in Indoor Air. Procedia Engineering, 121, 1939-1947. https://doi.org/10.1016/j.proeng.2015.09.183

Maharashtra Pollution Control Board (MPCB) Mumbai (2016). Comprehensive action plan for control of air pollution with focus on control of VOC's in Mahul, Ambapada and Chembur area. Available at https://www.mpcb.gov.in/sites/default/files/focus-area-reportsdocuments/Draft\%20 action_plan_Mahul_Ambapada_Air_Pollution_10012018.pdf

Mei, S., Hu, J., Liu, D., Zhao, F., Li, Y., Wang, Y., \& Wang, H. (2017). Wind driven natural ventilation in the idealized building block arrays with multiple urban morphologies and unique package building density. Energy \& Buildings, 155, 324-338. https://doi.org/10.1016/j.enbuild.2017.09.019

Merlier, L., Kuznik, F., Rusaouën, G., \& Salat, S. (2018). Derivation of generic typologies for microscale urban air flow studies. Sustainable Cities and Society. 36(December 2016), 71-80. https://doi.org/10.1016/j.scs.2017.09.017

Michael M. Cernea. (1995). Understanding and Preventing Impoverishment from Displacement. Journal of Refugee Studies, 8(3), 245-264. https://doi.org/10.1093/jrs/8.3.245-

Montazeri, H., Blocken, B., Janssen, W., \& Hooff, T. Van. (2012). CFD analysis of wind comfort on high-rise building balconies: validation and application. Iawe.Org, 1674-1681. Retrieved from http://www.iawe.org/Proceedings/BBAA7/H.Montazeri.pdf

Naik, Y. (2018). SRA slammed over slum rehab near refinery. Mumbai Mirror.

Raman, R., \& Roy, U. K. (2019). Taxonomy of urban mixed land use planning. Land Use Policy, 88(August), 104102. https://doi.org/10.1016/j.landusepol.2019.104102

Ramponi, R., Blocken, B., de Coo, L. B., \& Janssen, W. D. (2015). CFD simulation of outdoor ventilation of generic urban configurations with different urban densities and equal and unequal street widths. Building and Environment, 92, 152-166.

https://doi.org/10.1016/j.buildenv.2015.04.018

Roberts, J. J., Croke, E. J., Booras, S., Roberts, J. J., Croke, E. J., \& Booras, S. (1975). A critical review of the Effect of Air Pollution Control Regulations on Land use Planning. Journal of the Air Pollution Control Association, 25(5), 500-520. https://doi.org/10.1080/00022470.1975.10470107

Romagny, L. (2004). Resettlement: An Alternative for Upland Development? In Shifting Cultivation and Poverty Eradication in the Iplands of the Lao PDR: NAFRI Workshop Proceedings (pp. 117-128).

Romero, H., Ihl, M., Rivera, A., Zalazar, P., \& Azocar, P. (1999). Rapid urban growth , land-use changes and air pollution in Santiago, Chile. Atmospheric Environment, 33(1999), 4039-4047. https://doi.org/10.1016/S1352-2310(99)00145-4

Šalkauskienè, V., Gudritienè, D., \& Abalikštienė, E. (2019). Analysis of the non-productive land use in Lithuania. Land Use Policy, 80(October 2018), 135-141. https://doi.org/10.1016/j.landusepol.2018.10.010

Sarkar, A., \& Bardhan, R. (2018). Optimizing Interior Layout for Effective Experiential Indoor Environmental Quality in Low-income Tenement Unit: A Case of Mumbai, India. Building Simulation \& Optimization Conference, (September), 11-12.

Sarkar, A., \& Bardhan, R. (2019a). A simulation based framework to optimize the interior design parameters for effective Indoor Environmental Quality ( IEQ ) experience in affordable residential units : Cases from Mumbai , India. IOP Conf. Ser.: Earth Environ. Sci., 294(012060). https://doi.org/10.1088/1755-1315/294/1/012060 
Sarkar, A., \& Bardhan, R. (2019b). Optimal interior design for naturally ventilated low-income housing : a design-route for environmental quality and cooling energy saving. Advances in Building Energy Research, O(0), 1-33. https://doi.org/10.1080/17512549.2019.1626764

Sarkar, A., \& Bardhan, R. (2020a). Improved indoor environment through optimised ventilator and furniture positioning: A case of slum rehabilitation. Frontiers of Architectural Research, (xxxx). https://doi.org/10.1016/j.foar.2019.12.001

Sarkar, A., \& Bardhan, R. (2020b). Socio-physical liveability through socio-spatiality in low-income resettlement archetypes - A case of slum rehabilitation housing in Mumbai, India. Cities, 105. https://doi.org/10.1016/j.cities.2020.102840

Sholihah, P. I., \& Shaojun, C. (2018). Impoverishment of induced displacement and resettlement ( DIDR ) slum eviction development in Jakarta Indonesia. International Journal of Urban Sustainable Development, 10(3), 263-278. https://doi.org/10.1080/19463138.2018.1534737

Shroff, K., Raø, P., \& Pathak, B. K. (2019). Report of KEM Hospital on The issue for consideration is air pollution in the outskirts of Mumbai affecting inhabitants of the area, particularly at villages Ambapada and Mahul since 2007.

Slum Rehabilitation Authority. (2017). Slum Rehabilitation Scheme, DCR 33 (10).

Taleai, M., Sharifi, A., Sliuzas, R., \& Mesgari, M. (2007). Evaluating the compatibility of multifunctional and intensive urban land uses. International Journal of Applied Earth Observation and Geoinformation, 9, 375-391. https://doi.org/10.1016/j.jag.2006.12.002

Tominaga Yoshihide, Mochida Akashi, Yoshie Ryuichiro, Kataoka Hiroto, Nozu Tsuyoshi, Yoshikawa Masaru, \& Shirasawa Taichi. (2008). AIJ guidelines for practical applications of CFD to pedestrian wind environment around buildings. Journal of Wind Engineering and Industrial Aerodynamics, 96(10-11), 1749-1761. Retrieved from http://www.sciencedirect.com/science/article/B6V3M-4S92XJB3/2/6fa25de97bffea6eac85b9eadf2155e https://doi.org/10.1016/j.jweia.2008.02.058

Wang, H., Shen, Q., Tang, B., \& Skitmore, M., (2013). An integrated approach to supporting land-use decisions in site redevelopment for urban renewal in Hong Kong. Habitat International, 38, 7080. http://dx.doi.org/10.1016/j.habitatint.2012.09.006

Weinstein, L. (2012). "Slum-free Mumbai" and other entrepreneurial strategies in the making of Mumbai's global downtown (pp. 234-252).

Weng, Q., \& Yang, S. (2006). Urban air pollution patterns, land use , and thermal landscape : an examination of the linkage using GIS, 463-489. https://doi.org/10.1007/s10661-006-0888-9

Wilmsen, B., Adjartey, D., \& Hulten, A. Van. (2019). Challenging the risks-based model of involuntary resettlement using evidence from the Bui Dam, Ghana. International Journal of Water Resources Development, 0627, 1-19. https://doi.org/10.1080/07900627.2018.1471390

Yuan, C., \& Ng, E. (2012). Building porosity for better urban ventilation in high-density cities - A computational parametric study. Building and Environment, 50, 176-189. https://doi.org/10.1016/j.buildenv.2011.10.023

Zhang, A., Gao, C., \& Zhang, L. (2005). Numerical simulation of the wind field around different building arrangements. Journal of Wind Engineering and Industrial Aerodynamics, 93(12), 891904. https://doi.org/10.1016/j.jweia.2005.09.001

Zhang, Z., Liu, J., \& Gu, X. (2019). Land Use Policy Reduction of industrial land beyond Urban Development Boundary in Shanghai : Differences in policy responses and impact on towns and villages. Land Use Policy, 82(October 2018), 620-630. https://doi.org/10.1016/j.landusepol.2018.12.040 
Zhou, C., Wang, Z., Chen, Q., Jiang, Y., \& Pei, J. (2014). Design optimization and field demonstration of natural ventilation for high-rise residential buildings. Energy and Buildings, 82, 457-465. https://doi.org/10.1016/j.enbuild.2014.06.036 